\title{
CAFFEINE DOES NOT MODULATE NUTRITIVE BLOOD FLOW TO RAT GASTRIC SUBMUCOSA - A MICRODIALYSIS STUDY
}

\author{
Norbert Cibicek $^{\mathrm{a} *}$, Helena Zivna ${ }^{\mathrm{b}}$, Jaroslav Cibicek ${ }^{\mathrm{c}}$, Eva Cermakova ${ }^{\mathrm{d}}$, Viktor Vorisek ${ }^{\mathrm{a}}$, \\ Jana Malakova ${ }^{a}$, Stanislav Micuda ${ }^{\mathrm{e}}$, Vladimir Palicka ${ }^{\mathrm{a}}$
}

\author{
a Institute of Clinical Biochemistry and Diagnostics, \\ b Radioisotope Laboratories and Vivarium, \\ d Computer Technology Center, \\ e Department of Pharmacology, Charles University, Prague, Faculty of Medicine in Hradec Králové and University Hospital \\ Hradec Králové, Czech Republic, \\ c Department of Pathology, "Forlife" General Hospital, Komárno, Slovak Republic \\ e-mail: cibicek@seznam.cz
}

Received: February 20, 2008; Accepted (with revisions): April 15, 2008

Key words: Caffeine/Microcirculation/Nitric oxide/Microdialysis/Rat

Background and Aims: Coffee irritates the gastric mucosa disrupting its barrier and increasing the risk of peptic ulcers. However, caffeine's contribution to these effects has not yet been elucidated. In this study we looked at the local effect of caffeine on the microcirculation and nitric oxide production in rats together with systemic marker of oxidative stress malondialdehyde as possible mechanisms whereby caffeine might participate in mucosal barrier impairment.

Materials and Methods: Four groups of rats were anesthetized and administered as a bolus four different intraperitoneal doses of caffeine $\left(0,1,10\right.$ and $50 \mathrm{mg} \mathrm{kg}^{-1}$ b.wt.). The gastric submucosal microcirculation and nitric oxide production were then recorded for 2.5 hours by in situ microdialysis using the flow marker ethanol. At the completion of the experiments, plasma caffeine and malondialdehyde levels as well as morphological mucosal injury were determined.

Results: There were no major differences in the macro- or microscopic pictures of the mucosa among the groups. Local microcirculatory (ethanol out/in ratio) and nitric oxide monitoring failed to demonstrate statistically significant changes as did measurement of plasma malondialdehyde in response to caffeine injections.

Conclusions: Caffeine per se seems unlikely to contribute to the gastric mucosal barrier injury associated with coffee consumption by alterations in nutritive blood flow, nitric oxide production or aggravation of systemic oxidative stress. This information is relevant for better understanding of the mechanisms involved in caffeine-mediated influences on gastric physiology in relation to the irritant effects of coffee.

\section{INTRODUCTION}

Caffeine (contained in coffee, tea, caffeinated beverages, cocoa, chocolate etc.) is the most consumed stimulant drug of abuse worldwide. With regard to coffee, epidemiological data support its irritant role in stomach and esophagus in association with gastroesophageal reflux leading to enhanced risk of ulcers and cancer in the afflicted areas ${ }^{1,2}$. Recently, this irritant effect was also confirmed in young asymptomatic individuals ${ }^{3}$. The beverage is a complex mixture of possibly antagonistic substances comprising, apart from caffeine, isoflavones, polyphenols, diterpenes etc. exhibiting effects according to the type of coffee bean processing ${ }^{4,5}$. To elucidate the cause of the irritant nature of coffee to the stomach, focusing on the effects of isolated and purified (pharmacologically) active components of coffee would lead to more information. Of these components caffeine is the most studied.

Maintenance of the gastric mucosal barrier integrity is dependent on the balance between aggressive and protective factors represented by hydrochloric acid on one hand and adequate mucosal blood flow with sufficient mucus production on the other. Caffeine, a known acid secretagogue, has long been suspected of causing mucosal hypoperfusion due to (micro)vascular impairment ${ }^{6}$. This hypothesis was later supported by electron microscopy ${ }^{7}$. More recent observations report suppressed acetylcholine (ACh)-induced mucus production ${ }^{8}$ by caffeine and gastric mucosal transmembrane potential difference ${ }^{9}$, completing the barrier-braking mosaic picture of caffeine. However, the aforementioned notion has been challenged by experimental observations showing enhanced mucosal blood flow by caffeine ${ }^{10}$ and a protective influence of this drug on mucosal barrier integrity ${ }^{11}$ suggesting actually a preventive role for caffeine in gastric mucosal injury ${ }^{12}$.

Caffeine is a methylxanthine with pluripotent and possibly opposing pharmacological actions. It is a nonselective adenosine receptor antagonist, phosphodiesterase inhibitor, ryanodine-sensitive $\mathrm{Ca}^{2+}$ channel activator and soluble guanylate cyclase (GC) inhibitor. As a consequence, these actions may interfere with nitric oxide (NO) production and/or its second messenger cyclic guanosine monophosphate (cGMP) pathway leading to modulation of a wide spectrum of mucosal barrier-related (patho)physiological effects exerted by NO including vascular tone regulation or modulation of oxidative stress 
level ${ }^{13}$. The literature, to the best of our knowledge, provides rather limited data on caffeine's effect on gastric (sub)mucosal microcirculation and has not included parallel monitoring of local NO release (using microdialysis), so far. Similarly, the putative effect of caffeine on oxidative stress necessitates clarification. The aim of the present study was twofold: first, to evaluate the possible impact of caffeine on gastric submucosal microcirculation, nitric oxide production and morphology, and second, to measure plasma malondialdehyde (MDA) as a marker of oxidative stress (lipid peroxidation).

\section{MATERIALS AND METHODS}

\section{Animals}

Conventionally bred adult white male Wistar rats (Biotest s.r.o., Konárovice, Czech Republic) weighing 300-400 g, were used. The animals were housed in the animal quarters for at least 7 days prior to experiments under controlled environmental conditions. The rats had free access to standard pellets (ST 1-TOP, Velas, Prague, Czech Republic) except for the 16-18 h before experiments, when they were fasted. Tap water was provided ad libitum until the day of the experiment. All animals received humane care in accordance with the guidelines set by the institutional Animal Use and Care Committee of the Charles University, Prague, Faculty of Medicine in Hradec Králové, Czech Republic. All experimental procedures were approved by the same committee.

\section{Animal preparation}

All animals were anesthetized with single i.p. dose of pentobarbital (50 mg kg-1 Nembutal $^{\circledR}$, Abbott Laboratories, North Chicago, USA) and placed in a supine position on an unheated bed. They were kept under general anesthesia by cyclic i.p. administration of Nembutal $^{\circledR}\left(15 \mathrm{mg} \mathrm{kg}^{-1} \mathrm{~h}^{-1}\right)$. Body temperature was monitored using a rectal thermometer probe (Ama-digit ad $15^{\text {th }}$, Aprecision, Germany) and maintained at $37.5-38.0^{\circ} \mathrm{C}$ by means of a heating lamp. The trachea was cannulated with a short polyethylene catheter to ensure patent airways.

\section{Substances}

For microdialysis, ethanol-enriched normal $0.9 \%$ saline (final concentration $50 \mathrm{mmol}^{-1}$ ) $^{14}$ was used as a perfusion medium. Caffeine (purchased from SigmaAldrich, St. Louis, MO, USA) was dissolved in normal saline to obtain solutions with concentrations $0.5,5$ and $25 \mathrm{mg} \mathrm{ml}^{-1}$ for groups 2,3 and 4 , respectively.

\section{Gastric submucosal microdialysis technique}

Modified technique originally described by Kitano et al. ${ }^{15}$ was used. Briefly, following 3-4 cm long midline laparotomy, stomach was exposed. Firstly, respecting the course of blood vessels, a $21 \mathrm{G}$ needle was introduced into the submucosa of gastric fundus with care neither to penetrate through the mucosa into the lumen nor to make an additional opening in the serosa. Secondly, a microdi- alysis probe (MAB 11.8.10 with $6 \mathrm{kDa}$ cut-off polyethylene suplhone membrane, active length $10 \mathrm{~mm}$; outer diameter $0.5 \mathrm{~mm}$; Microbiotech/se AB, Stockholm, Sweden) was cautiously inserted into the preformed tunnel (Fig. 1a). Finally, the probe was fixed to the serosa with a suture. Continuous microdialysis was effectuated by perfusing the catheters with ethanol solution by means of CMA 102 microdialysis pump (CMA Microdialysis AB, Solna, Sweden) at a perfusion rate of $2 \mu 1 \mathrm{~min}^{-1}$. For tissue equilibration, an initial 60 min period (without specimen collection) was allowed which was succeeded by a $30 \mathrm{~min}$ period to yield the baseline sample. Thereafter, sampling ensued for the next $2.5 \mathrm{~h}$ in $30 \mathrm{~min}$ intervals into sterile $200 \mu$ polyethylene microvials. The specimens were aliquoted and stored at $-70{ }^{\circ} \mathrm{C}$ (for nitric oxide) or $-20{ }^{\circ} \mathrm{C}$ (for ethanol) until analysis.

\section{Experimental design}

The animals were randomly allocated to four groups ( 6 in each). After the collection of baseline microdialysis sample, the first (sham-operated) group received by intraperitoneal injection an adequate volume of normal saline, whereas the second, third and fourth groups were intraperitoneally administered caffeine solutions with concentrations $0.5,5$ and $25 \mathrm{mg} \mathrm{ml}^{-1}$ (caffeine dose of 1,10 and $50 \mathrm{mg} \mathrm{kg}^{-1} \mathrm{~b}$. wt.) respectively. At the conclusion of experiments, the animals were sacrificed by blood withdrawal from abdominal aorta. The obtained plasma was stored at $-70{ }^{\circ} \mathrm{C}$ for ensuing biochemical determination of caffeine and MDA. After the removal of stomach from the body, the mucosal surface of the glandular part was gently cleaned in cold tap water and closely inspected in search for macroscopic lesions. The tissues surrounding the probe $(0.5 \times 1.5 \mathrm{~cm})$ with the probe itself in situ were then dissected and the biopsy immersed in $10 \%$ formaline for histological examination.

\section{Probe performance stability \\ and in vivo recovery determination for nitrate}

The measurement of NO using microdialysis technique was validated in two consecutive steps employing other two groups (A and B) of pentobarbital-anesthetized rats. First, probe performance stability for nitrate was tested continuously for $7 \mathrm{~h}$ (measurements during equilibration period inclusive, group $A, n=5$ ) in one experiment based on an assumption of stable NO production throughout the study period. Microdialysis sampling in gastric submucosa was realized in 30 min intervals at a perfusion rate of $2 \mu \mathrm{l} \mathrm{min}{ }^{-1}$. As perfusate, normal saline was utilized. Second, in vivo recovery of the same probe type was estimated (group B, $\mathrm{n}=3$ ) using zero-net flux method originally proposed by Lönnroth et al. ${ }^{16}$. Four perfusion media of increasing concentrations of sodium nitrate in sterile saline were consecutively applied as follows. After the initial tissue equilibration $\left(1 \mathrm{~h}\right.$ ) with $10 \mu \mathrm{mol} \mathrm{l}^{-1} \mathrm{NaNO}_{3}$, a 30 min sample was collected. The perfusion medium was changed for $15 \mu \mathrm{mol} \mathrm{l}^{-1}$ nitrate and following $30 \mathrm{~min}$ equilibration, another sample harvest (30 min) ensued respecting the probe's lag time ( $3 \mathrm{~min})$. The experiment 

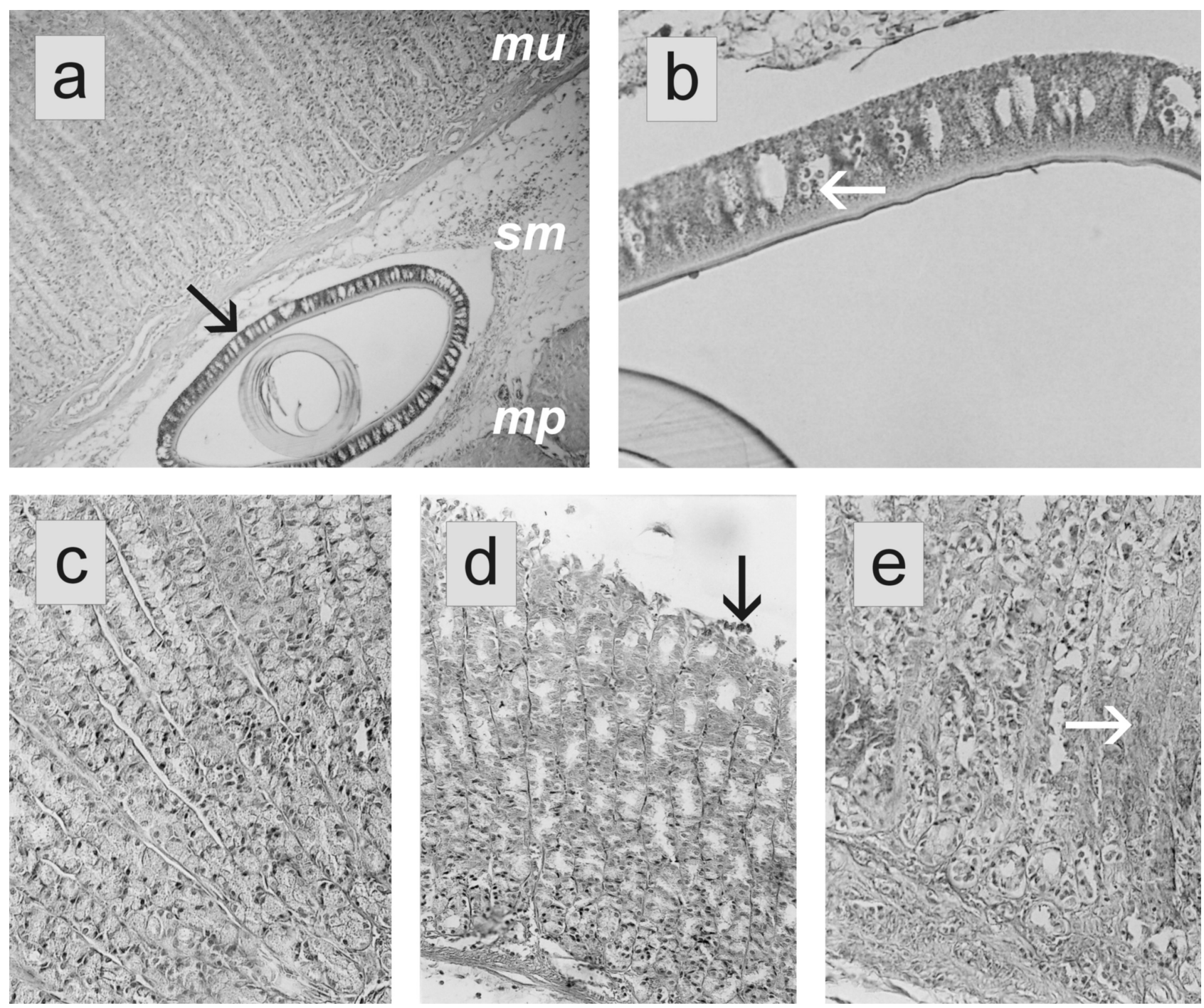

Fig. 1. Morphological studies. Panel "a" confirms the position of the microdialysis probe within the submucosal layer of gastric wall (arrow). The catheter is surrounded by noticeable edema and hyperemia with diffuse inflammatory infiltrate of mild degree penetrating at some places into the mucosa. The probe's tougher inner membrane was slightly damaged during tissue slicing $(\mathrm{mu}=$ mucosa, $\mathrm{sm}=$ submucosa, $\mathrm{mp}=$ muscularis propria $)$. Panel "b" depicts the detail of the probe's outer membrane permeated by polymorphonuclear leukocytes (arrow). Pictures "c-e" show normal gastric mucosa, i. e. grade 0, and typical lesions of grade I and II - detached cells and necrosis of pits (arrows), respectively. Standard hematoxylin-eosine stain, original magnification "a" 125×, "b" 500×, "c-e" 250×.

was completed with 50 and finally $120 \mu \mathrm{mol} \mathrm{l}^{-1}$ nitrate solutions. The results were plotted on a graph and probe recovery was read from the regression equation (slope gradient). Besides microdialysis, these two groups of animals underwent no further experimental treatment. All general steps (anesthesia, surgery, gastric submucosal microdialysis technique including probes but excluding perfusion media, sacrifice and analytical techniques) were equal to the experimental groups of the present study.

\section{Nutritive blood flow measurement}

Using flow marker (e.g. ethanol)-enriched perfusion medium, microdialysis offers opportunity to indirectly assess tissue microcirculation (nutritive blood flow) in various organs. The principle of the so called "ethanol dilution technique" is based on the negative correlation between blood perfusion and ethanol efflux from the probe represented by out/in ratio of ethanol concentrations $^{14,17,18}$.

\section{Biochemical analyses}

Total NO was quantitatively determined as the sum of its stable metabolites (nitrite plus nitrate) in an enzymatic colorimetric assay, which involves an enzymatic conversion of nitrate to nitrite by nitrate reductase. Resulting nitrite is detected colorimetrically as a colored azo dye product of the Griess reaction that absorbs visible light at $540 \mathrm{~nm}$. In the experiments commercially available 
ELISA kits (Assay Designs, Ann Arbor, MI, USA) were utilized only. All procedure steps were performed according to the manufacturer's instructions.

The analyses of ethanol were carried out using GC-MS apparatus consisting of Varian 3300 Gas Chromatograph (GC) coupled to Finnigan MAT Magnum Mass Spectrometer (MS; Thermo Fisher Scientific, formerly Finnigan). Supelcowax ${ }^{\mathrm{TM}}-10$ (30 $\mathrm{m}$ x $0.25 \mathrm{~mm}$ x $0.25 \mu \mathrm{m}$ film thickness) GC Capillary column with helium as a carrier gas was employed. Injector and transferline temperatures were set to $230{ }^{\circ} \mathrm{C}$ for both. GC oven was programmed as follows: $55^{\circ} \mathrm{C}, 2 \mathrm{~min}, 25^{\circ} \mathrm{C} \mathrm{min}-1$ to $150{ }^{\circ} \mathrm{C}$, hold for $1 \mathrm{~min}$. The specified MS parameters were $70 \mathrm{eV}$ for electron ionization mode (EI) and $209^{\circ} \mathrm{C}$ for ion trap temperature. The resulted MS spectra were scanned in 15-70 a.m.u. mass range under 4 microscans $\mathrm{s}^{-1}$ of detection speed regimen.

Plasma caffeine concentrations were determined using a modified HPLC method by Biederbick et al. ${ }^{19}$. Briefly, caffeine and internal standard hydroxyethyltheophylline (aqueous solution $\left.40 \mathrm{mg} \mathrm{l}^{-1}\right)$ from plasma samples (100 $\mu \mathrm{l}$ $+50 \mu \mathrm{l}$ ) were extracted using $2.5 \mathrm{ml}$ of dichlormethane. The organic phase was evaporated under nitrogen at $40{ }^{\circ} \mathrm{C}$ and the samples were reconstituted in $150 \mu$ of mobile phase, and $30 \mu \mathrm{l}$ were injected into the HPLC column. Analysis was performed on a 2695 Waters Separations Module equipped with 996 photodiode array detector and Peltier column-thermostat Jet-Stream (Thermotechnic Products). The mobile phase was made up of an aqueous solution of sodiumdihydrogenphosphate $\left(0.5 \mathrm{mmol} \mathrm{l}^{-1}\right.$, $\mathrm{pH}$ 5) to acetonitrile (ratio 88:12) and was pumped iso-

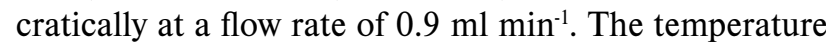
of the column was set at $40{ }^{\circ} \mathrm{C}$. The quantification of caffeine was performed at $270 \mathrm{~nm}$.

Plasma MDA was determined as a secondary product of lipid peroxidation in an attempt to evaluate the level of oxidative stress produced by caffeine. The analysis was based on the reaction of MDA with thiobarbituric acid (TBA) producing a red MDA-TBA complex measured photometrically at three distinct wavelengths (485, 532 and $560 \mathrm{~nm}$ ) and the absorbance corrected according to Allen's formula $A_{\text {corr }}=A_{532}-\left[\left(A_{560}-A_{485}\right) \times 0.63+A_{485}\right]$ for enhanced specificity ${ }^{20}$.

\section{Histological analyses}

Stomach biopsies were taken to evaluate possible effects of caffeine on tissue morphology at microscopic level and for probe position verification. The samples $(0.5 \times$ $1.5 \mathrm{~cm}$ ) were taken from glandular segment surrounding the probe. The tissues were fixed in $10 \%$ neutral buffered formalin and further treated according to standard procedures for hematoxylin-eosin (HE) stain. The sections were evaluated by a blinded professional observer and photographed at 125, 250 and 500-fold magnification. The grading criteria were adopted from Natale et al. and were as follows: grade 0 for normal mucosa, grade I for lysis and segregation of cells on the luminal surface (with intact pit cells), grade II for damage confined to gastric pits with detachment of the surface epithelium and grade III

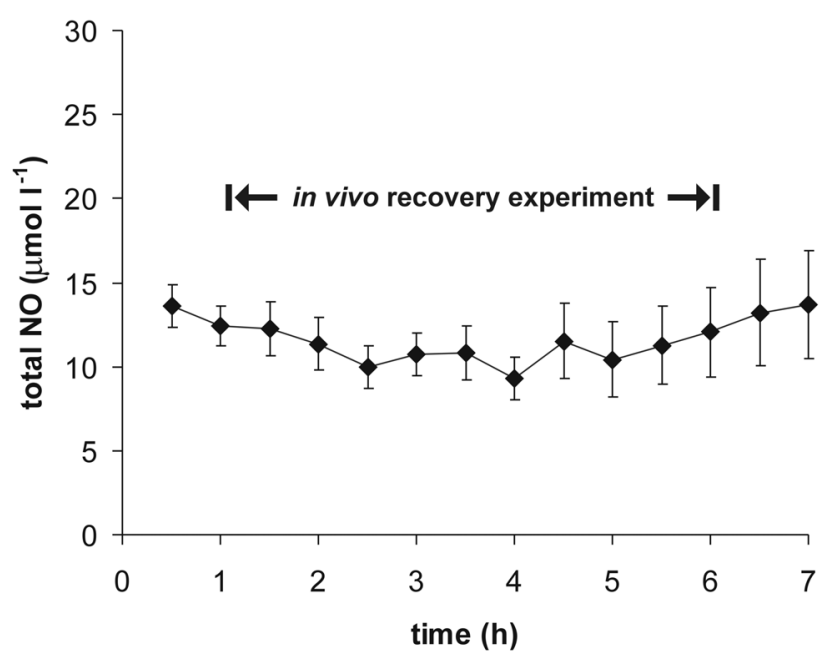

Fig. 2. The graph depicts total gastric submucosal nitric oxide (NO) production (presented as a sum of nitrite and nitrate), as monitored in anaesthetized rats by in vivo microdialysis and confirms its stability throughout the experiment. The arrows specify the time frame of in vivo recovery determination (measured in another study, see Fig. 3). Data are expressed as means \pm SEM of 5 measurements.

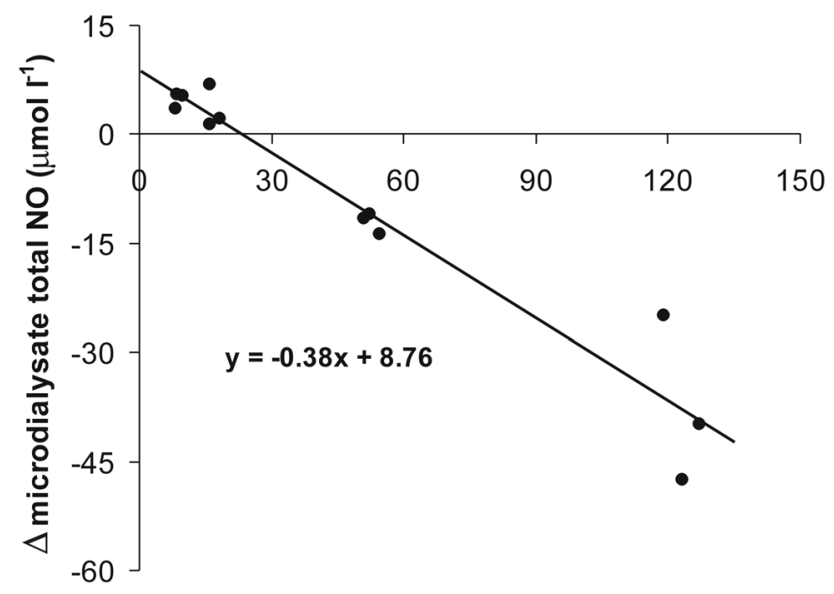

perfusate total NO $\left(\mu \mathrm{mol} \mathrm{I}^{-1}\right)$

Fig. 3. In vivo probe calibration ("zero net-flux" method). The $\Delta$ microdialysate (dialysate - perfusate) total NO plotted against the perfusate total NO gives a gradient representing the probe's recovery (38\%). The $\mathrm{x}$-intercept corresponds to the concentration of NO in the surrounding extracellular medium $\left(\sim 23 \mu \mathrm{mol} \mathrm{l}^{-1}\right)$. The y-intercept approximates the mean concentration obtained in due course from stability experiment ( $11 \mu \mathrm{mol} \mathrm{l}^{-1}$, Fig. 2). Single results of three animals are displayed as dots. 
which involves injured gastric glands (whole-thickness mucosal necrosis with swelling and possible disconnection of mucosal layers $)^{21}$.

\section{Statistics}

Data are expressed as means \pm standard error of mean (SEM), unless otherwise noted. For statistical evaluation, normality tests and repeated measures ANOVA were used. The data were processed by the program NCSS 2004. The chosen level of significance was $\alpha=0.05$.

\section{RESULTS}

\section{Histology}

Microdialysis probes were positioned correctly within the submucosal layer of gastric wall without penetration into the organ's lumen. The histological picture was comparable to previous reports ${ }^{15,22}$ as indicated in Fig. 1a, b. Lack of macroscopically measurable whole organ mucosal alterations due to caffeine treatment was mirrored in standard microscopy, which depicted similar grades of tissue damage ranging within grades 0 -II around the probe in slides from all experimental groups including sham-operated animals (Fig. 1c-e). The severity of mucosal injury was unrelated to the administered caffeine dose. No grade III lesions were observed.

\section{Microdialysis data}

The results of probe performance stability are displayed in Fig. 2. In this experiment, the calculated average outflow concentration of total NO (within 5 h-time frame corresponding with the probe calibration study) was $11 \mu \mathrm{mol} \mathrm{l}^{-1}$. This is in agreement with the expected value $\left(\sim 9 \mathrm{~mol} \mathrm{l}^{-1}\right)$ calculated using extrapolation of data obtained from the probe calibration study, i.e. in case the concentration of total NO in the perfusate was close to zero (Fig. 3). The outcomes of these experiments were consistent with one another indicating stable function of the microdialysis probe and NO production over time. The in vivo recovery of the used probe type under given experimental conditions was determined by the gradient of the regression line and found to be $38 \%$. The x-intercept corresponds to the concentration of nitrite + nitrate in the surrounding extracellular medium $\left(\sim 23 \mu \mathrm{mol} \mathrm{l}^{-1}\right.$, Fig. 3$)$. This level of extracellular NO was not affected by the i.p. administration of caffeine ( $p=0.9$, ANOVA, Fig. 4a). The microcirculation as represented by the ethanol out/in ratio showed a tendency for dose-related alterations after caffeine but the difference was not statistically significant $(\mathrm{p}=0.1$, ANOVA, Fig. 4b).

\section{Plasma analytes}

Along with caffeine, plasma MDA was measured as general oxidative stress-related marker at the conclusion of the experiments. Even here, no statistically significant dose-related trend was observed $(\mathrm{p}=0.8$, ANOVA, Tab. 1).
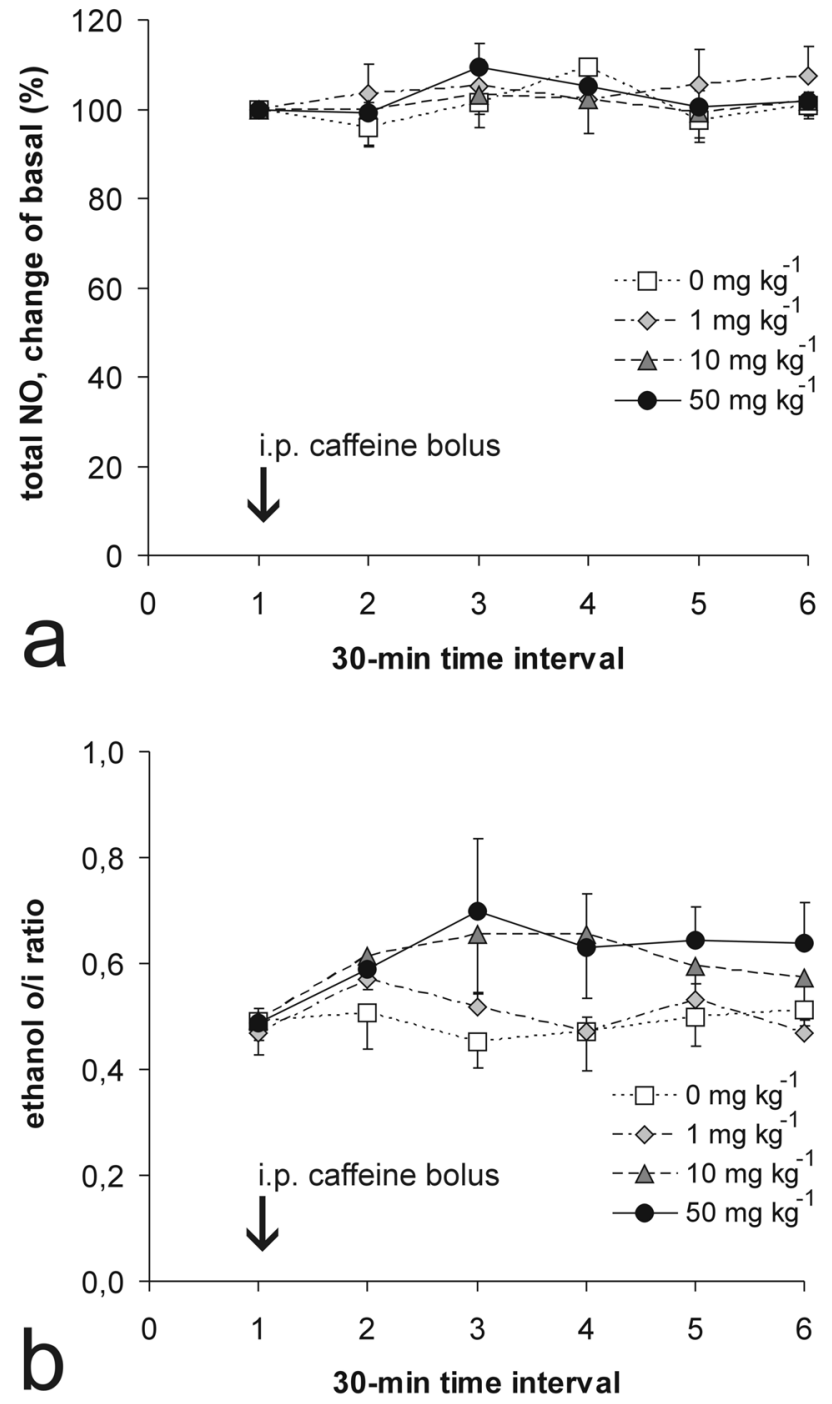

Fig. 4. Panel "a" presents the total NO production in response to increasing caffeine load. No difference was registered within $2.5 \mathrm{~h}$ of monitoring. Panel " $b$ " illustrates the time course of microdialysate ethanol out/in ratio (negatively correlates with nutritive blood flow) indicating a slight tendency of microcirculation to deteriorate in a dose-dependent manner (particularly at intervals 3 and 5) following the injection of caffeine. However, this trend lacks statistical significance. Results are means \pm SEM of 6 measurements.

\section{DISCUSSION}

\section{Effect of caffeine on (sub)mucosal morphology}

Even though macroscopical observations (e.g. a computerized planimetry) are a "golden standard" in the evaluation of gross gastric mucosal injury for their ability to assess the whole organ, they are inconvenient for detection and scoring of minor (visibly hardly discernible) changes. Since, in accordance with literature ${ }^{23}$, the latter was also the case in our experiment, gastric mucosal impairment was studied microscopically using standard 
histology. However, owing to the exactingness of the suggested method of whole organ histological evaluation ${ }^{21}$, we decided for the present time to grade the most prominent cellular/tissue changes found in comparable parts of glandular stomachs (in the vicinity of probe implantation site) of experimental groups. Since this time we did not quantify the lesions, the statistical approach was not feasible. Hence, the present study provides only qualitative data on the effects of microdialysis and caffeine on rat gastric tissue morphology.

\section{NO measurement using microdialysis}

There is very limited data on gastric NO measurement with in vivo microdialysis. Iversen et al. measured nerve-induced release of NO in the wall of rabbit stomach. They utilized different probe types (CMA/10, CMA Medical AB, Stockholm, Sweden, 3 x $0.7 \mathrm{~mm}$ dialysis membrane with $20 \mathrm{kDa}$ cut-off) and perfusion rate ( $1 \mu \mathrm{l}$ $\left.\min ^{-1}\right)$ and estimated interstitial concentrations of nitrite and nitrate to approximate 10 and $70 \mu \mathrm{mol} \mathrm{l}^{-1}$, respectively. The calculated in vitro recovery of the probes (for given perfusion rate) equaled 31 - $33 \%$ for nitrate and nitrite, respectively. The authors did not determine the recovery in vivo, but assumed that it would be in the range 10-40 \% ${ }^{24}$. Suzuki et al. recently employed similar probes to our catheters (MAB 7.8.10 with $15 \mathrm{kDa}$ cut-off dialysis membrane, active length $10 \mathrm{~mm}$; outer diameter $0.5 \mathrm{~mm}$; Microbiotech/se AB, Stockholm, Sweden) and validated them for studying nitrosative chemistry in the lumen of human stomach. The assessed in vitro recovery for nitrite at $\mathrm{pH} 1.5$ and perfusion rate $0.15 \mathrm{ml} \mathrm{h}^{-1}$ was $71 \%{ }^{25}$. Our results of in vivo recovery may be comparable to these studies since the dialysis function of membranes in vivo generally diminishes ${ }^{16}$. The interstitial concentration of total NO found in our study $\left(\sim 23 \mu \mathrm{mol} \mathrm{l}^{-1}\right)$ was lower than reported by Iversen et al. in rabbits. It is a matter of debate to what extent this difference may be attributable to species and/or technique used.

\section{Effect of caffeine on $\mathrm{NO}$ production}

Besides vascular tone regulation, nitric oxide released by $\mathrm{Ca}^{2+}$-dependent endothelial (e)NOS as well as $\mathrm{Ca}^{2+}$ independent inducible (i)NOS plays a large number of (patho)physiological roles many of which may be related to mucosal defence and injury ${ }^{13}$. It is therefore of interest whether caffeine interferes with the release of this reactive pluripotent radical. Bruce et al. report of a significant decrease in exhaled NO levels in humans one hour after 100-200 mg caffeine intake ${ }^{26}$. The latest findings indicate that caffeine (16 $\mathrm{mg} \mathrm{kg}^{-1}$ i.v.) may decrease nitric oxide synthase (NOS) expression in rat skeletal muscles ${ }^{27}$ and attenuate glutamate-induced NO synthesis in murine spinal cord in vitro ${ }^{28}$. Moreover, caffeine negates the protective effect of ischemic preconditioning, i.e. eliminates reactive hyperemia due to the hypoperfusion-induced accumulation of adenosine and enhanced NO production ${ }^{29}$. In contrast, endothelium of isolated rat aorta responds to caffeine by promotion of NO synthesis ${ }^{30}$. In the present study, we failed to detect significant shifts in NO production up to $2.5 \mathrm{~h}$ after the application of increasing doses of caffeine. However, eNOS releases NO in nanomolar quantities, changes we may have been unable to detect with the analytical procedure we used while micromolar amounts of NO are produced by activated iNOS as soon as $2 \mathrm{~h}$ after application of inducing substance ${ }^{31}$. Therefore, our results indicate no effect of caffeine on $\mathrm{Ca}^{2+}$-independent NO production in resting gastric submucosa of anesthetized rats.

\section{Effect of caffeine on blood flow}

Despite the generally recognized constricting role of caffeine in the brain ${ }^{32}$, heart ${ }^{33}, \operatorname{limb}^{34}$ or gut $^{35}$ vasculature, the literature is inconsistent as far as gastric (sub)mucosal perfusion is concerned. Understandably, the discrepancy with respect to blood flow is reflected in the contrary effects of caffeine on acute induced gastric mucosal injury ${ }^{36,23,12}$. Ozturkcan et al. showed that a single i.p. injection of 7.5 - $30 \mathrm{mg} \mathrm{kg}^{-1}$ caffeine leads to elevations in rat gastric mucosal blood flow 90 min after drug application ${ }^{10}$. Moreover, Koyama et al. found that ex vivo intraluminal administration of caffeine doses as high as 50-100 mg kg-1 result in a dose-dependent increase in mucosal blood flow lasting up to $90 \mathrm{~min}^{12}$. Although in the present study some tendencies to decreased nutritive blood flow could be observed 30-90 min after caffeine administration, the results show a lack of statistically significant change in this variable throughout the experiment (Fig. 4b). This would be consistent with other studies showing no direct effect of caffeine on resting blood flow ${ }^{37-39}$ and/or induced vascular contractility ${ }^{40}$. Along these lines, there is conflict-

Table 1. The table summarizes the effect of increasing doses of caffeine on plasma caffeine and malondialdehyde (MDA) levels at the conclusion of experiments. In spite of a negative trend, no statistically significant difference or association between administered caffeine and plasma MDA was found. Data are displayed as means \pm SEM of 6 measurements.

\begin{tabular}{|l|c|c|c|c|}
\hline $\begin{array}{l}\text { i. } \text { p. caffeine dose } \\
\left(\mathrm{mg} \mathrm{kg}^{-1} \text { b.wt. }\right)\end{array}$ & 0 & 1 & 10 & 50 \\
\hline $\begin{array}{l}\text { plasma caffeine } \\
\left(\mathrm{mg} \mathrm{l}^{-1}\right)\end{array}$ & $0 \pm 0.00$ & $1.43 \pm 0.07$ & $11.80 \pm 0.42$ & $56.51 \pm 1.68$ \\
\hline $\begin{array}{l}\text { plasma MDA } \\
\left(\mu \mathrm{mol} \mathrm{l}^{-1}\right)\end{array}$ & $0.94 \pm 0.05$ & $0.91 \pm 0.12$ & $0.84 \pm 0.03$ & $0.80 \pm 0.15$ \\
\hline
\end{tabular}


ing data on the effect of caffeine on endothelial function. Papamichael et al. describe acute detrimental effects of caffeine up to $90 \mathrm{~min}$ after oral intake of $80 \mathrm{mg}$ of caffeine on endothelium-dependent flow-mediated dilatation of the brachial artery ${ }^{41}$ whereas Umemura et al. report its favorable role on (acetylcholine-induced) forearm vasodilation one hour after oral administration of $300 \mathrm{mg}$ of caffeine, whereas baseline blood flow remained unaltered ${ }^{37}$. Interestingly, the latter authors ascribe these findings to enhanced endothelial NO synthesis caused by released $\mathrm{Ca}^{2+}$ from endoplasmic reticulum through activation of ryanodine-sensitive $\mathrm{Ca}^{2+}$ channels and the suppression of cGMP degradation ${ }^{30}$, while the former investigators account for their observation as the inhibitory effect of caffeine on soluble GC with eventual suppression of cGMP formation. Unfortunately, neither group measured real in situ NO production. Nevertheless, these explanatory discrepancies may have some rationale as the differential pharmacologic actions of caffeine depend on the plasma caffeine levels ${ }^{42}$. Hence, the final vasoactive action of caffeine may result from a balance between its vasoconstrictive (adenosine-antagonizing) and possibly vasodilating (NO-releasing) ability.

\section{Effect of caffeine on oxidative stress}

There are data suggesting multifarious mechanisms whereby caffeine might play a role in augmenting oxidative stress ${ }^{41}$. However, the acute unfavorable consequence of caffeine could also follow from its antagonism with adenosine - a substance producing NO and thus preventing mitochondrial oxidant damage in rat cardiomyocytes ${ }^{43}$. In rats that underwent concussive head injury, Al Moutaery et al. demonstrated an increase in the level of inflammation and oxidative stress (significant increase in neutrophil infiltration and brain MDA) associated with a dose-dependent increase in mortality of caffeine-pretreated animals ${ }^{44}$. In the present experiment, the plasma concentrations of caffeine were consonant with previous findings ${ }^{45}$ and indicate good bioavailability of caffeine after i.p. application. However, $2.5 \mathrm{~h}$ after drug administration, only a slight dose-dependent decreasing trend of plasma MDA levels lacking statistical significance was noted. This indicates no acute detrimental effect of caffeine on whole body's oxidative stress as far as systemically manifested effects are concerned (Tab. 1).

\section{CONCLUSIONS}

The results of the present study indicate that i.p. administration of caffeine in given dosages does not produce acute macroscopic changes to gastric mucosa and is unlikely to alter gastric submucosal nutritive blood flow and nitric oxide production or aggravate systemic oxidative stress level. Additional histomorphometric studies are needed to describe the effect of caffeine on gastric mucosa and further attempts need to be made to explore possible mechanisms whereby caffeine might participate in irritant effects of coffee.

\section{ABBREVIATIONS}

cGMP - cyclic guanosine monophosphate

GC - guanylate cyclase

MDA - malondialdehyde

NO - nitric oxide

e/iNOS - endothelial/inducible nitric oxide synthase

\section{ACKNOWLEDGEMENTS}

The authors acknowledge skillful technical assistance of Mrs. Ježková in the vivarium, Mrs. Menclová and Mrs. Lošonská in the biochemical and histopathological laboratories, respectively. This work was supported by Research Project from the Czech Ministry of Foreign Commerce MZO 00179906.

\section{REFERENCES}

1. Marotta RB, Floch MH. Diet and nutrition in ulcer disease. Med Clin North Am 1991; 75(4):967-79.

2. Terry P, Lagergren J, Wolk A, Nyren O. Reflux-inducing dietary factors and risk of adenocarcinoma of the esophagus and gastric cardia. Nutr Cancer 2000; 38:186-91.

3. Cibickova L, Cibicek N, Zdansky P, Kohout P. The impairment of gastroduodenal mucosal barrier by coffee. Acta Medica (Hradec Králové) 2004; 47(4):275-8.

4. Ehrlich A, Basse H, Henkel-Ernst J, Hey B, Menthe J, Lücker PW. Effect of differently processed coffee on the gastric potential difference and intragastric $\mathrm{pH}$ in healthy volunteers. Methods Find Exp Clin Pharmacol 1998; 20(2):155-61.

5. Fiebich BL, Valente P, Ferrer-Montiel A, Candelario-Jalil E, Menthe J, Luecker P. Effects of coffees before and after special treatment procedure on cell membrane potentials in stomach cells. Methods Find Exp Clin Pharmacol 2006; 28(6):369-72.

6. Roth JA, Ivy AC. The pathogenesis of caffeine-induced ulcers. Surgery 1945; 17:644-9.

7. Pfeiffer CJ, Roth JLA. Studies on the secretory and cytotoxic actions of caffeine on the ferret gastric mucosa. Exp Mol Pathol 1970; 13:66-78.

8. Hamada E, Nakajima T, Hata Y, Hazama H, Iwasawa K, Takahashi $\mathrm{M}$ et al. Effect of caffeine on mucus secretion and agonist-dependent $\mathrm{Ca} 2+$ mobilization in human gastric mucus secreting cells. Biochim Biophys Acta 1997; 1356(2):198-206.

9. Dziaduś-Sokołowska A, Orlef A, Bilski R, Mroczka J. The effect of ethanol-caffeine interaction on the gastric mucosal barrier. Pol J Pharmacol Pharm 1989; 41(3):253-8.

10. Ozturkcan O, de Saint Blanquat G, Derache R. Effet de la cafféine sur le flux sanguin de la muqueuse gastrique chez le Rat. Thérapie 1974; 29:941-4.

11. Wittmers LE, Alich A, Quirk DR. Effect of caffeine on the Gastric Potential Difference (GPD). FASEB Journal 1998; 12(5):A737.

12. Koyama R, Kataoka H, Tanaka Y, Nakatsugi S, Furukawa M. Effect of caffeine on ibuprofen-induced gastric mucosal damage in rats. $\mathrm{J}$ Pharm Pharmacol 1999; 51(7):817-24.

13. Elliott S, Wallace JL. Nitric oxide: a regulator of mucosal defence and injury. J Gastroenterol 1998; 33:792-803.

14. Arner P, Hellmér J, Hagström-Toft E, Bolinder J. Effect of phosphodiesterase inhibition with amrinone or theophylline on lipolysis and blood flow in human adipose tissue in vivo as measured with microdialysis. J Lipid Res 1993; 34:1737-43.

15. Kitano M, Norlén P, Håkanson R. Gastric submucosal microdialysis: a method to study gastrin- and food-evoked mobilization of ECL-cell histamine in conscious rats. Regul Pept 2000; 86:11323. 
16. Lönnroth P, Jansson PA, Smith U. A microdialysis method allowing characterization of intercellular water space in humans. Am J Physiol 1987; 253(2):228-31.

17. Hickner RC, Ekelund U, Mellander S, Ungerstedt U, Henriksson J. Muscle blood flow in cats: comparison of microdialysis ethanol technique with direct measurement. J Appl Physiol 1995; 79(2):638-47.

18. Korth U, Krieter H, Denz Ch, Janke Ch, Ellinger K, Bertsch T et al. Intestinal ischaemia during cardiac arrest and resuscitation: comparative analysis of extracellular metabolites by microdialysis. Resuscitation 2003; 58:209-17.

19. Biederbick W, Joseph G, Rump A, Theisohn M, Klaus W. Caffeine in Saliva After Peroral Intake: Early Sample Collection as a Possible Source of Error. Therapeutic Drug Monitoring 1997; 19:521-4.

20. Hendrix T, Assman R. Spectrophotometric correction for bile pig ments in the thiobarbituric test for malondialdehyde-like substances in plasma. Med Lab Sci 1990; 47:10-6.

21. Natale G, Lazzeri G, Blandizzi C, Gherardi G, Lenzi P, Pellegrini A et al. Seriate histomorphometry of whole rat stomach: an accurate and reliable method for quantitative analysis of mucosal damage. Toxicol Appl Pharmacol 2001; 174:17-26.

22. Cibiček N, Mičuda S, Chládek J, Živný P, Zadák Z, Čermáková E et al. Lithium microdialysis and its use for monitoring of stomach and colon submucosal blood perfusion - a pilot study using ischemic preconditioning in rats. Acta Medica (Hradec Králové) 2006; 49(4):227-31.

23. Parmar NS, Tariq M, Ageel AM. Effect of nicotine, alcohol and caffeine pretreatment on the gastric mucosal damage induced by aspirin, phenylbutazone and reserpine in rats. Jpn J Pharmacol 1985; 39(1):1-6.

24. Iversen HH, Celsing F, Leone AM, Gustafsson LE, Wiklund NP. Nerve-induced release of nitric oxide in the rabbit gastrointestinal tract as measured by in vivo microdialysis. Br J Pharmacol 1007; 120:702-6

25. Suzuki H, Moriya A, Iijima K, McElroy K, Fyfe VE, McColl KEL. Validation of microdialysis probes for studying nitrosative chemistry within localized regions of the human upper gastrointestinal tract. Scand J Gastroenterol 2003; 38:856-63.

26. Bruce C, Yates DH, Thomas PS. Caffeine decreases exhaled nitric oxide. Thorax 2002; 57:361-3.

27. Corsetti G, Pasini E, Assanelli D, Saligari E, Adobati M, Bianchi R. Acute caffeine administration decreased NOS and Bcl2 expression in rat skeletal muscles. Pharmacol Res 2007; 55(2):96-103.

28. Godfrey L, Bailey I, Toms NJ, Clarke GD, Kitchen I, Hourani SM. Paracetamol inhibits nitric oxide synthesis in murine spinal cord slices. Eur J Pharmacol 2007; 562(1-2):68-71.

29. Riksen NP, Zhou Z, Oyen WJG, Jaspers R, Ramakers BP, Brouwer $\mathrm{RMHJ}$ et al. Caffeine prevents protection in two human models of ischemic preconditioning. J Am Coll Cardiol 2006; 48:700-7.
30. Hatano Y, Mizumoto K, Yoshiyama T, Yamamoto M, Iranai H. Endothelial-dependent and -independent vasodilatation of isolated rat aorta induced by caffeine. Am J Physiol 1995; 269:H1679-84.

31. Huang CJ, Tsai PS, Pan WHT, Skimming JW. Microdialysis for measurement of hepatic and systemic nitric oxide biosynthesis in septic rats. Acta Anaesthesiol Scand 2005; 49:28-34.

32. Couturier EG, Laman DM, van Duijn MA, van Duijn H. Influence of caffeine and caffeine withdrawal on headache and cerebral blood flow velocities. Cephalalgia 1997; 17(3):188-90.

33. Bottcher M, Czernin J, Sun KT, Phelps ME, Schelbert HR. Effect of caffeine on myocardial blood flow at rest and during pharmacological vasodilation. J Nucl Med 1995; 36(11):2016-21.

34. Casiglia E, Bongiovi S, Paleari CD, Petucco S, Boni M, Colangeli $\mathrm{G}$ et al. Haemodynamic effects of coffee and caffeine in normal volunteers: a placebo-controlled clinical study. J Intern Med 1991; 229(6):501-4.

35. Hoecker Ch, Nelle M, Poeschl J, Beedgen B, Linderkamp O. Caffeine impairs cerebral and intestinal blood flow velocity in preterm infants. Pediatrics 2002; 109(5):784-7.

36. Yano S, Isobe Y, Harada M. The etiology of caffeine-induced aggravation of gastric lesions in rats exposed to restraint plus waterimmersion stress. J Pharmacobiodyn 1982; 5(7):485-94.

37. Umemura T, Ueda K, Nishioka K, Hidaka T, Takemoto H, Nakamura $\mathrm{S}$ et al. Effects of acute administration of caffeine on vascular function. Am J Cardiol 2006; 98:1538-41.

38. Wierema TK, Houben AJ, Kroon AA, Postma CT, Koster D, van Engelshoven JM et al. Mechanisms of adenosine-induced renal vasodilatation in hypertensive patients. J Hypertens 2005; 23(9):17316.

39. Daniels JW, Mole PA, Shaffrath JD, Stebbins CL. Effects of caffeine on blood pressure, heart rate, and forearm blood flow during dynamic leg exercise. J Appl Physiol 1998; 85(1):154-9.

40. Barton B, Kleinert JM. The effect of caffeine on digital haemodynamics. J Hand Surg [Br] 1994; 19(3):301-2.

41. Papamichael CM, Aznaouridis KA, Karatzis EN, Karatzi KN, Stamatelopoulos KS, Vamvakou G et al. Effect of coffee on endothelial function in healthy subjects: the role of caffeine. Clin Sci (Lond) 2005; 109(1):55-60.

42. Fredholm BB, Battig K, Holmen J, Nehlig A, Zvartau EE. Actions of caffeine in the brain with special reference to factors that contribute to its widesptread use. Pharmacol Rev 1999; 51:83-133.

43. Xu Z, Park SS, Mueller RA, Bagnell RC, Patterson C, Boysen PG. Adenosine produces nitric oxide and prevents mitochondrial oxidant damage in rat cardiomyocytes. Cardiovasc Res 2005; 65(4):803-12.

44. Al Moutaery K, Al Deeb S, Khan HA, Tariq M. Caffeine impairs short-term neurological outcome after concussive head injury in rats. Neurosurgery 2003; 53(3):704-12.

45. Wang Y, Lau ChE. Caffeine has similar pharmakokinetics and behavioral effects via the IP and PO routes of administration. Pharmacol Biochem Behav 1998; 60(1):271-8. 